\title{
Discussion on Auto Logo Design Evolution from the Auto Brand Development
}

\author{
Sisi Zhang \\ Academy of Arts and Films \\ Chengdu University \\ Chengdu, China
}

\author{
Lijuan Xiong \\ Academy of Arts and Films \\ Chengdu University \\ Chengdu, China
}

\author{
Yueru Zhuo \\ Academy of Arts and Films \\ Chengdu University \\ Chengdu, China
}

\begin{abstract}
The auto logo design symbolizes an auto brand image and historical culture, it contains the development process and characteristics of the time that a brand has, and it is a tool for the auto brand to disseminate brand culture and spirit. However, the logo design of an auto brand is not fixed, and instead, it is varying with the time. This article, based on the analysis of the relations between auto logo design and auto brand development, summarizes the predominant trend of current auto logo design through a series of samples.
\end{abstract}

Keywords —auto brand; logo design

\section{INTRODUCTION}

In 1889, the first auto logo co-founder Rene Panhard and Emile Levassor had initials of their names namely $\mathrm{L}$ and $\mathrm{P}$ as symbols to make it distinguished from others, from then on, the auto logo has become the optimal method to distinguish auto brands. For an auto brand, starting from the initial identification function up to now, it has had more functions and been further used as a symbol, showing a brand spirit and inclusion and representing a brand quality, credit and principle and further the reflection on the time, nation, national personality and characteristics. Just for this purpose, it is necessary for the auto logo design and development to vary with the brand and the time.

\section{ABout Auto Logo Design}

First of all, auto logo is the first symbol visual for auto brand and a representation of auto brand. As an extracted image and symbol, it reflects the cultural inclusion of auto brand, disseminating the brand spirit to the public and leaving a profound and good impression to the people.

Auto logo design is the first step for auto brand design and a major tool for auto cultural dissemination. An excellent logo design can have an auto brand culture disseminated

This work was supported by Automotive Creative Design Pilot Area of Chengdu University and Longquanyi District under grant 2015-CX00-00010-ZF. accurately; on the contrary, an incorrect logo design may cause the brand culture and tenet to be vague, harmful to the brand. Therefore, before making an auto logo design, we should fully understand and analyze the history and culture related to the auto brand, as well as its development orientation and goals. With these conditions ready as well as the background of the time such as politics, economy and culture considered, we can extract the elements showing brand culture and characteristics of the time in order for a significant creativity.

Auto brand logo design styles are diverse, and different brands have stories of their own on the logo design. For example, some auto brand adopt animal images as main elements for logo design, some directly adopt English letters as logo and some adopt abstracted geometric design or 3D figures as auto logos. However, whatever the combination is, acting as the first visual symbol of brand, the auto logo should not be complicated designs, whose design combination shall also keep it seen visually beautiful. In the meantime, the logo design styles shall go with the time, having characteristics of originality and implicative combinations. For outdated or dull design styles cannot reflect basic identification function as auto logos and are reduced seriously to attract the public as well. Hence, the auto logo design should adopt the most simple symbol visual to directly express the cultural inclusion and development orientation of an auto brand.

\section{RELATIONS BETWEEN AUTO BRAND DEVELOPMENT AND LOGO DESIGN}

Any auto logo design is based on some contents of its own for development, and its changes every time are firmly related to the brand development and characteristics of the time, which is a necessity for a brand development.

The auto logo design should have diverse contents and styles, and every auto brand has unique and exclusive logo of its own. With the time going and brand upgrade, the auto logo will change with it as well, and the inclusion it carries is 
more and more complicated. The auto logo design just goes in a trend ranging from complex to simple and concrete to abstract.

\section{A. Take French Auto Brand Peugeot Logo as an Example}
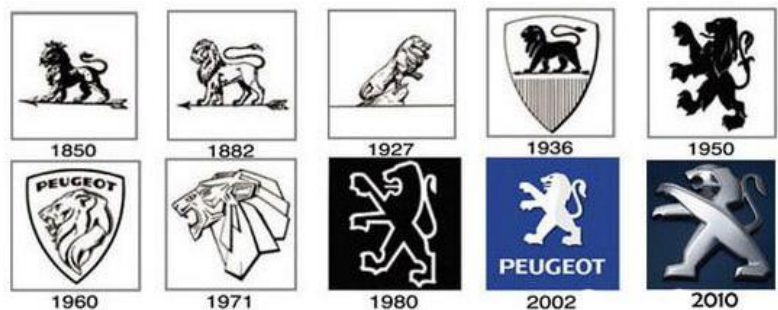

Fig. 1. French auto Peugeot evolutions.

Initially influenced by the industrial revolution, Peugeot company was a metal such as hacksaw blades manufacturer in France, so the initial logo design adopted "Male Lion", an emblem of Montbliard, where the company was established, hoping that the male lion symbols the excellent and good toughness of its products. The whole logo was just a lion walking on an arrow, which was very common and concrete, just like sketch of a lion in "Fig. 1".

With the development of auto industry, Peugeot Company turned to the auto manufacturing industry, correspondingly its logo just changed as well. The initial logo lion was simplified into a lion profile added with shield and English names. Main reasons for the logo improvement included: first, due to the brand upgrade, the original logo design was unable to fully reflect the cultural inclusion it wanted to show; second, going with the time and design tide, the logo design was simplified and abstracted. Hence the auto logo design just varies with the time.

With the brand development, the Peugeot logo was improved gradually. Up to 1980, the Peugeot logo got a breakthrough, and the rudiment of modern Peugeot came into being. At that time, the logo design started to adopt grounding, the design was still a lion, but its styles had been greatly changed, and the whole design became a profile of a lion standing in roaring. The figure was simple with stiff lines supported by background and white lines, the logo seemed simple but profound, and the whole logo design was more simple and fashionable.

In 2010, the Peugeot logo was renewed once again, and the design changed from $2 \mathrm{D}$ to $3 \mathrm{D}$. And the $3 \mathrm{D}$ elements were the design styles popular and hot for the public at that time. And the new abstracted and geometric logo looked flexible, find, full and extensive, showing an enterprise culture being pursuing high quality permanently. The lion element was a reflection of great brand witnessing more than a hundred years, and the 3D design makes it comfortable in metal, making it stable and decorous, winning credits from consumers.
B. Take German Auto Mercedes-Benz Logo As An Example
1893

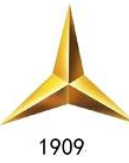

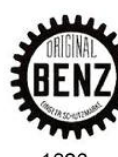
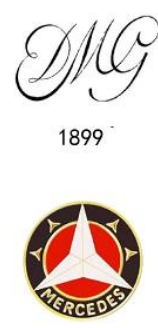

1916
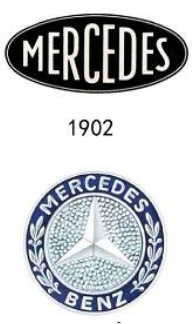

1926
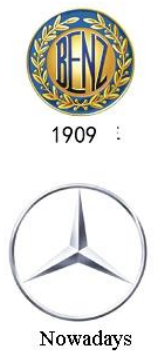

Fig. 2. German auto Mercedes-Benz logo evolutions.

Except Peugeot auto, the world famous German auto brand Mercedes-Benz logo three-pointed start also has a long story of evolution, which is another typical case. MercedesBenz was established through the merger of a company owned by Karl Benz, father of auto, and a company owned by Gottlieb Daimler in 1926 in "Fig. 2".

Before the merger, the logo designs of the two companies developed as well. In 1903, the Benz logo adopted letters ORIGINAL BENZ added with gear-shaped out ring. The world ORIGINAL meant primitive, initial and exclusive, showing the initiative of Karl Benz as auto investor. Gear was a typical symbol of mechanical industry, showing the high quality of Benz. In 1909, Benz removed the world ORIGINAL out of the logo with Benz left only; the gear out ring was replaced by laurel flower. The laurel flower represents victory and champion in matches, which showed the excellent results of Benz in auto events.

In 1902, Daimler Auto Company registered MERCEDES as trademark, which was a combination of an ellipse and MERCEDES. At that time, MERCEDES was a name of an investor's daughter at the company, which in Spanish meant good luck. In 1909, the company changed the logo into a three-pointed star, the inspiration originated from a postcard. The three-pointed star on the postcard was thought to bring good luck to his family, showing his ideal of development for sea, air and lands. In 1916, the three-pointed star was combined with MERCEDES, added with an outer ring. Daimler Company hoped that the new logo would bring auto owners good luck. Seen from the above, the publicity focus in auto industry was changing from mechanism to client service, which was also the rudiment of Mercedes-Benz in the next years.

After the two companies were merged in 1926, the logo design integrated and continued previous elements, added with BENZ and laurel flower with the three-pointed star, ring and MERCEDES remained, forming a new logo, which symbolized a brand merger.

In 1933, Mercedes-Benz simplified the log design and removed all English letters, only remaining three-pointed star and a ring, besides, the color of the original logo was cancelled, and white background and black figure were used to form the logo. The change was a significant milestone of Mercedes-Benz logo design, marking the logo changing from complexity to simplicity. 
Just like French Peugeot brand, in 1989, Mercedes-Benz changed its logo from plane to $3 \mathrm{D}$, and a sense of metal was adopted to represent the design style simple and fashionable at that time, which up to now is popular in the public.

In a word, auto logo design is closely related to the auto brand development, and the development of the time promotes the auto brand upgrade gradually, and the auto brand upgrade also promotes the optimization of auto brand logo design. We can see that a good brand or logo design, whatever changes are, is always based on certain cultural background. Any auto logo design should follow the development tide, integrating enterprise spirits and regional culture to the graphic language.

\section{OVERLOOK CHINESE AUTO LOGO DESIGN}

We are in the time of Made in China, it is urgent for develop a national brand. At the beginning of Chinese reforms, most of Chinese auto logos designs borrowed or copied famous auto brands, and the auto logos with the same animal images could be found everywhere. The development of national brand has to be based on our cultural origin, showing the self-confidence of culture, considering the long term brand development according to the time tide, and combining modern design with traditional Chinese cultural elements for inheritance and innovation.

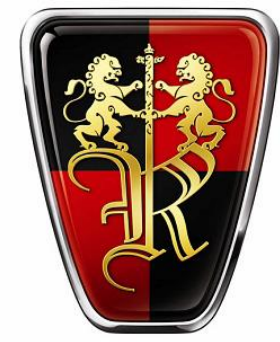

Fig. 3. ROEVE auto logo.

ROEVE is an auto brand released by Shanghai SAIC Motor in Oct 2006, meaning "Honored innovation, Famous around the world", the brand integrated Chinese and western cultures, open and reserved, elegant and self-confident. The logo design adopted traditional Chinese cultural elements: magnificent and duo-lion. Traditional elements are supported with three classic colors namely black, red and golden, fully showing the brand noble, wise and august. The magnificent stuff is a pole standing before palace in ancient China, symbolizing dignity, grandness and inviolability. Black, red and golden are traditional Chinese colors, representing prestige, happiness and luxury. The whole logo is a combination of Chinese and western culture, full of confidence, and fully interpreting the faith of independent operation and innovation of SAIC Motor and the resolution and confidence of carrying forward world advanced techniques and creating a brand new international brand based in China in "Fig. 3".

Seen from the above, the logo design of national brands should be more based on Chinese culture and combine traditional culture with modern design, being deep in brand culture and development orientation.

\section{CONCLUSION}

Auto logo design evolution and auto brand development are supporting each other and closely related. When an auto brand develops with the time, in order to meet the requirements of enterprise culture and marking, the logo design should be renewed in time, besides, its development orientation and step shall follow the time pulse and brand spirits. In the meantime, the auto logo is the best slogan for brand promotion and the optimal bulletin board to form a brand image. If Chinese brands need follow and even overpass international famous ones, the logo design must be based on traditional Chinese culture and soil, with the tradition inherited and brand culture conceived, it should follow the tide of the time and go with the time, rejecting the outdated and introducing the most advanced.

\section{REFERENCES}

[1] Zhao Wei, Animal Symbol and Auto Logo Design [J]. Art \& Design (Theory), 2010,2(06):80-82.

[2] Chen Shaoming, Discussion on Auto Logo Design [J]. Art Science and Technology, 2014,27(05):234.

[3] Liu Yichun, Discussion on Characteristics of Auto Logo Design and Graphic Shaping [J]. Brand, 2014,(02):9.

[4] Han Han, Analyze the Influences of Minimalism through Auto Design Development [J]. Beauty and Time (Mid), 2012,(04):78-79.

[5] Ke Mengjie, Discussion on Design Though Ranging from Complexity to Simplicity - based on Auto Brand Visual Images [J]. Art of Design (Journal of Shandong University of Art and Design), 2017,(02):33-37.

[6] Zhang Chengzhong, Ming Yue, Application of Totem in Modern Auto Logo Shaping [J]. Technological Development of Enterprise, 2009,28(10):41+50.

[7] Chen Zhanxiao, Discussion on Auto Logo Culture and Evolution [J]. Art and Literature for the Masses, 2011,(15):75.

[8] Zhang Zheli, Research on Chinese Auto Brand Logo Design [D]. Jingdezhen Ceramic Institute, 2014 